\title{
Birch Pollen IgG Measurement
}

National Cancer Institute

\section{Source}

National Cancer Institute. Birch Pollen IgG Measurement. NCI Thesaurus. Code C130074.

A measurement of the birch pollen IgG in a biological specimen. 